\title{
Pelaksanaan Akad Mudharabah Pada Pembiayaan Modal Usaha di Koperasi Dewan Kemakmuran Masjid At-Taqwa Desa Cicadas Kecamatan Sagalaherang Kabupaten Subang
}

\author{
Siti Rahmah Ramadhan ${ }^{1}$, Ahmad Damiri ${ }^{2}$, Jalaludin ${ }^{3}$ \\ ${ }^{1}$ STAI Riyadhul Jannah \\ ${ }^{23}$ STIES Indonesia Purwakarta \\ Jln. Veteran no 150-152 Purwakarta 41118 Jawa Barat INDONESIA \\ ${ }^{1}$ Ramadhansitirahmah@gmail.com \\ 2ahmad.damiri86@gmail.com \\ 3 jalaludin.darululum@yandex.com
}

\begin{abstract}
Abstrak_Artikel ini membahas tentang pelaksanaan akad mudharabah pada pembiayaan modal usaha di Koperasi Dewan Kemakmuran Masjid Desa Cicadas Kecamatan Sagalaherang Kabupaten Subang. Tujuan dari penelitian ini adalah untuk mengetahui pelaksanaan akad mudharabah pada pembiayaan modal usaha di Koperasi Dewan Kemakmuran Masjid At-Taqwa Desa Cicadas, mengetahui penentuan bagi hasil di Koperasi Dewan Kemakmuran Masjid At-Taqwa Desa Cicadas, dan untuk mengetahui dampak dari pelaksanaan pembiayaan Akad Mudharabah pada Koperasi Dewan Kemakmuran Masjid At-Taqwa Desa Cicadas. Metode penelitian yang digunakan adalah penelitian kualitatif dengan pendekatan empiris. Teknik pengumpulan data yang digunakan adalah observasi, wawancara, dan dokumentasi. Dalam penelitian ini, sumber data terdiri dari Data Primer dan Data Sekunder. Data Primer diperoleh dari hasil lapangan dengan cara observasi dan wawancara langsung dengan Ketua Koperasi Dewan Kemakmuran Masjid At-Taqwa Desa Cicadas. Data sekunder diperoleh dari berbagai referensi, seperti sumber dari internet, arsip-arsip lembaga dan bacaan lain yang berhubungan dengan masalah yang diteliti. Hasil penelitian menunjukan bahwa pelaksanaan akad mudharabah pada pembiayaan modal usaha di Koperasi Dewan Kemakmuran Masjid At-Taqwa Desa Cicadas hanya menggunakan satu jenis akad pada pembiayaan mudharabah yaitu muqayyadah. Sistem bagi hasil yang diterapkan menggunakan prinsip profit sharing dengan pengembalian modal dilakukan dengan melakukan pembayaran angsuran yang dilakukan dengan jangka waktu sesuai dengan kemampuan mudharib. Dengan adanya pembiayaan tersebut mereka bisa dengan tenang menjalankan usaha yang mereka kelola tanpa adanya kekhawatiran dalam melaksanakannya, karena pembiayaan yang mereka jalankan merupakan pembiayaan yang diterapkan sesuai prinsip syariah Islam.
\end{abstract}

Kata Kunci : Riba, Bagi Hasil, Mudharabah, Profit Sharing, Muqayyadah.

Abstract_ This article discusses the implementation of the mudharabah contract on venture capital financing in the Cooperative Council for the Prosperity of the Mosque of Cicadas Village, Sagalaherang Sub-District, Subang Regency. The purpose of this study was to determine the implementation of mudharabah contracts on venture capital financing in the At-Taqwa Mosque Prosperity Cooperative Cooperative at Cicadas Village, determine the profit sharing determination at the At-Taqwa Mosque Prosperity Cooperative Council at Cicadas Village, and to determine the impact of the Mudharabah Akad financing scheme on Co-operative Prosperity Board of At-Taqwa Mosque, Cicadas Village. The research method used is qualitative research with an empirical approach. Data collection techniques used were observation, interviews, and documentation. In this study, the data source consisted of Primary Data and Secondary Data. Primary data were obtained from field results by direct observation and interviews with the Chairperson of the At-Taqwa Mosque Prosperity Council Cooperative in Cicadas Village. Secondary data was obtained from various references, such as sources from the internet, institutional archives and other readings related to the problem under study. The results showed that the implementation of the mudharabah agreement in 


\section{EKSISBANK Vol. 3 No. 2 Desember 2019}

business capital financing in the co-prosperity Board of the At-Taqwa Mosque Cicadas Village only used one type of contract on mudharabah financing, namely muqayyadah. Profit sharing system that is applied using the principle of profit sharing with a return on capital is done by making installment payments made in accordance with the ability of mudharib. With this funding they can calmly run the business they manage without any worries in carrying it out, because the financing they run is a financing that is implemented according to Islamic sharia principles.

Keywords: Riba, Profit Sharing, Mudharabah, Profit Sharing, Muqayyadah.

\section{PENDAHULUAN}

Perkembangan pemikiran ekonomi sudah ada sejak zaman Rasulullah SAW. Sistem ekonomi yang diterapkan pada zaman Rasulullah SAW berasal dari Al-Qur'an. Al-Qur'an sebagai petujuk bagi umat manusia dalam melakukan aktifitas di setiap aspek kehidupanya, termasuk dibidang ekonomi. Prinsip Islam yang paling mendasar adalah kekuasaan tertinggi hanya milik Allah SWT semata dan manusia diciptakan sebagai khalifah di muka bumi. Sebagai khalifah, manusia telah diciptakan dengan bentuk yang paling baik dari seluruh ciptaan lainnya seperti matahari, bulan, bintang, dan langit telah ditakdirkan untuk dimanfaatkan oleh manusia (Abdullah, 2010).

Islam memandang bahwa bumi dengan segala isinya merupakan amanah dari Allah SWT kepada sang khalifah agar dipergunakan dengan sebaik-baiknya untuk kesejahteraan bersama. Untuk mencapai tujuan yang suci ini, Allah SWT memberikan petunjuk dari para Rasul-Nya. Petunjuk tersebut meliputi segala sesuatu yang dibutuhkan manusia, baik aqidah, akhlak, maupun syariah.

Oleh karena itu, syariah Islam merangkum seluruh aspek kehidupan, baik dalam ibadah maupun sosial. Secara umum, tugas kekhalifahan adalah untuk mewujudkan kemakmuran dan kesejahteraan dalam hidup dan kehidupan serta tugas pengabdian atau ibadah maupun sosial. dalam arti luas untuk menunaikan tugas tersebut, Allah SWT memberikan manusia dua anugerah nikmat yaitu sistem kehidupan dan sarana kehidupan (Antonio, 2001).

Zaman modern seperti sekarang ini sudah banyak sekali lembaga keuangan yang menawarkan akad syariah. Seperti pada Koperasi Dewan Kemakmuran Masjid At-Taqwa yang berada di Desa Cicadas Kecamatan Sagalaherang Kabupaten Subang yang sudah menerapkan pelaksanaan akad syariah yaitu akad Mudharabah, salah satunya dalam pelaksanaan pembiayaan modal usaha.

Berdasarkan kehidupan masyarakat di sekitar, di mana sebagian besar masyarakat adalah seorang petani dan sebagian kecil masyarakat juga sudah memiliki usaha sendiri juga ditunjang dengan lokasi yang cukup sangat strategis. Lokasi tersebut berada di dekat jalan raya utama Desa Cicadas dan juga dibawah naungan Dewan Kemakmuran Masjid At-Taqwa yang menjadikan masyarakat di sekitar memiliki sifat yang agamis sehingga masyarakat sekitar selalu memegang teguh nilai-nilai syari'ah.

Koperasi DKM At-Taqwa Desa Cicadas menjunjung tinggi nilai-nilai keadilan, amanah, kemitraan, transfaransi dan saling menguntungkan bagi kedua belah pihak baik kepada mudharib maupun shahibul maal yang merupakan pilar-pilar dalam kegiatan mu'amalah. Oleh karena itu, produk yang disediakan bertujuan untuk memberikan solusi bagi masyarakat yang memiliki masalah dengan keuangan dan untuk kesejahteraan ekonomi masyarakat yang berdasarkan syariat Islam. Produk yang dimiliki berbagai macam penghimpunan dana dan penyaluran dana yang setiap produk tersebut mempunyai akad masingmasing, salah satu akad yang diterapkan dalam pelaksanaan ini adalah akad Mudharabah.

Pengertian Mudharabah secara bahasa berasal dari kata al-darb (الضزب) yang berarti bepergian atau berjalan. Selain al-darb disebut juga qiradh dari al-qardu (القزاض) berarti al-qath'u (القطع) yang berarti potongan. Muhammad Syafi'i Antonio dalam bukunya Bank Syari'ah dari Teori ke Praktek, menuliskan bahwa pengertian berjalan lebih tepatnya adalah proses seseorang dalam menjalankan usaha (Antonio, 2001).

Sedangkan dalam Fatwa DSN Nomor 07/DSN-MUI/IV/2000 disebutkan bahwa Mudharabah yaitu akad kerja sama suatu usaha antara dua pihak di mana pihak pertama (malik, shahih, al-mal, LKS) menyediakan seluruh modal, sedang pihak kedua (amil, mudharib, nasabah) bertindak sebagai pengelola, dan keuntungan usaha dibagi diantara mereka sesuai kesepakatan yang dituangkan dalam kontrak 
EKSISBANK Vol. 3 No. 2 Desember 2019

(Fatwa DSN Nomor 07/DSN-MUI/IV/2000 Tentang Pembiayaan Mudharabah). Dengan kata lain, Mudharabah adalah kerja sama dalam suatu usaha antara yang yang mempunyai modal dan keahlian dengan keuntungan dibagi dua berdasarkan kesepakatan.

Adapun dasar hukum pelaksanaan akad Mudharabah adalah firman Allah SWT. Dalam Al-Qur'an surat Al-Muzammil ayat 20 sebagai berikut (Hakim, 2011):

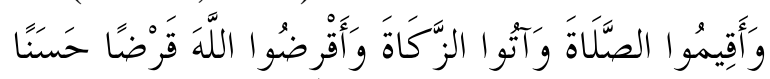

“...Dan dirikanlah shalat, tunaikanlah zakat dan berikanlah pinjaman kepada Allah pinjaman yang baik".

Selain Al-Qur'an, dasar hukum pelaksanaan akad Mudharabah dijelaskan juga dalam hadits Rasulallah SAW sebagai berikut, yang artinya (Al-Asqalany, 2019):

"Dari Shuhaib Radliyallaahu 'anhu bahwa Nabi Shallallaahu 'alaihi wa Sallam bersabda: "Tiga hal yang di dalamnya ada berkah adalah jualbeli bertempo, ber-qirad (memberikan modal kepada seseorang hasil dibagi dua), dan mencampur gandum dengan sya'ir untuk makanan di rumah, bukan untuk dijual)". (HR. Ibnu Majah dari Shuhaib).

Berdasarkan uraian di atas mengenai definisi dasar hukum dan syarat juga rukun dari akad tersebut, maka dapat dipahami bahwa akad Mudharabah adalah suatu akad perjanjian kerja sama antara dua pihak. Dimana salah satu pihak sebagai penyedia modal dan pihak lain adalah pengelola modal. Akad Mudharabah disebut sah apabila memenuhi syarat dan rukun yang sudah ditentukan.

Gambar 1. Skema Al-Mudharabah

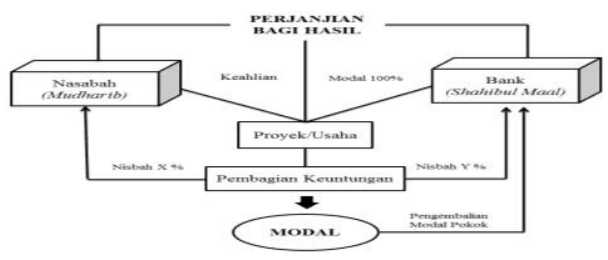

Sumber: Diolah oleh Peneliti Tahun 2019

Adapun tujuan dari penelitian ini adalah untuk mengetahui bagaimana pelaksanaan pembiayaan akad mudharabah pada Koperasi Dewan Kemakmuran Masjid At-Taqwa Desa Cicadas Kecamatan Sagalaherang Kabupaten Subang, penentuan bagi hasil pada pelaksanaan pembiayaan akad mudharabah pada Koperasi Dewan Kemakmuran Masjid At-Taqwa Desa Cicadas Kecamatan Sagalaherang Kaupaten
Subang, dan dampak pelaksanaan pembiayaan akad mudharabah pada Koperasi Dewan Kemakmuran Masjid At-Taqwa Desa Cicadas Kecamatan Sagalaherang Kabupaten Subang.

\section{Gambar 2. Kerangka Pemikiran Pembiayaan Akad} Mudharabah

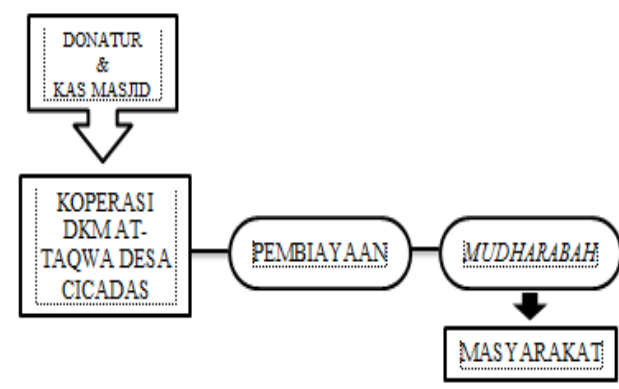

Sumber: Diolah oleh Peneliti Tahun 2019

\section{METODOLOGI PENELITIAN}

Metode yang digunakan dalam penelitian ini adalah metode studi kasus. Dengan menggunakan studi kasus ini, peneliti dapat mendeskripsikan atau memberikan gambaran suatu satuan analisis secara utuh sebagai suatu yang terintegritas. Dalam metode ini satuan analisis yang dimaksud berupa suatu penelitian yang dilakukan secara intensif, terinci dan mendalam terhadap suatu organisasi, lembaga atau gejala tertentu yang telah menjadi kebudayaan suatu masyarakat. Dalam hal ini Penulis akan mengumpulkan, mengelola, menganalisis data dan melaporkan hasil penelitian dengan objektif sesuai dengan hasil penelitian di lapangan. Penelitian deskriptif merupakan penelitian yang berusaha mendeskripsikan sesuatu (Arikunto, 2013).

Peneliti akan mencari tahu bagaimana pelaksanaan akad mudharabah pada pembiayaan modal usaha di Koperasi Dewan Kemakmuran Masjid At-Taqwa Desa Cicadas, mengetahui penentuan bagi hasil di Koperasi Dewan Kemakmuran Masjid At-Taqwa Desa Cicadas, dan untuk mengetahui dampak dari pelaksanaan pembiayaan Akad Mudharabah pada Koperasi Dewan Kemakmuran Masjid AtTaqwa Desa Cicadas.

Penelitian yang penulis gunakan menurut tiga studi kasus yang dijelaskan oleh Robert K Yin yaitu penelitian eksplanasi. Karena penelitian eksplanasi dimaksudkan agar peneliti lebih mengetahui dan mengembangkan konsep sesuai dengan keadaan di lapangan. Penelitian ini tidak harus dilakukan oleh orang yang sudah mahir 


\section{EKSISBANK Vol. 3 No. 2 Desember 2019}

dalam masalah yang diteliti tersebut. Orang atau masyarakat sering tidak puas hanya sekedar mengetahui apa yang terjadi, bagaimana terjadinya, tetapi juga ingin tahu mengapa hal tersebut bisa terjadi. Oleh sebab itu penulis bertujuan untuk mengkonfirmasi sebab terjadinya suatu masalah.

Data primer merupakan data yang diperoleh secara langsung oleh penulis dari responden terpilih pada lokasi penelitian. Data primer diperoleh dengan cara wawancara. Pada tanggal 30 Sepember 2019 Penulis mendatangi Koperasi Dewan Kemakmuran Masjid At-Taqwa Desa Cicadas Kecamatan Sagalaherang Kabupaten Subang, berbagai pertanyaan yang Penulis tanyakan seperti struktur organisasi, bagaimana pendapat mengenai akad mudharabah, pelaksanaan pembiayaan modal usaha dengan menggunakan akad mudharabah, siapa saja orang yang berhak menerima pembiayaan, produk apa saja yang tersedia di Koperasi Dewan Kemakmuran Masjid At-Taqwa Desa Cicadas Kecamatan Sagalaherang Kabupaten Subang.

Mengenai pelaksanaannya Penulis mencari tahu kepada Narasumber yaitu Bapak Haeri, beliau merupakan Ketua di Koperasi Dewan Kemakmuran Masjid At-Taqwa Desa Cicadas Kecamatan Sagalaherang Kabupaten Subang. Dengan begitu beliau mampu menjawab pertanyaan yang Penulis sampaikan atas dasar pengalaman yang beliau dapatkan.

Data sekunder merupakan data yang diperoleh dari jurnal, skripsi, situs internet, serta bacaan lain yang berhubungan dengan penelitian yang digunakan sebagai data penunjang untuk mengetahui bagaimana pelaksanaan akad mudharabah pada pembiayaan modal usaha di Koperasi Dewan Kemakmuran Masjid At-Taqwa Desa Cicadas, bagaimana sistem bagi hasil di Koperasi Dewan Kemakmuran Masjid At-Taqwa Desa Cicadas, serta dampak dari pelaksanaan akad mudharabah di Koperasi Dewan Kemakmuran Masjid At-Taqwa Desa Cicadas.

Adapun teknik pengumpulan data yaitu yang pertama observasi yaitu dengan melakukan pengamatan langsung terhadap objek yang diteliti, dalam hal ini Penulis sendiri mencoba menjadi mudharib/anggota di Koperasi Dewan Kemakmuran Masjid At-Taqwa Desa Cicadas. Kemudian wawancara merupakan pertemuan dua orang untuk bertukar informasi melalui tanya jawab dengan engajukan pertanyaan yaitu pengumpulan data yang dilakukan dengan cara memberikan daftar pertanyaan kepada di Koperasi Dewan Kemakmuran Masjid At-Taqwa Desa Cicadas yang mengetahui dan faham mengenai pelaksanaan akad mudharabah pada pembiayaan modal usaha di Koperasi Dewan Kemakmuran Masjid At-Taqwa Desa Cicadas Kecamatan Sagalaherang Kabupaten Subang.

Setelah mendapatkan data, kemudian penulis melakukan analisis data yang merupakan upaya untuk mencari secara sistematis hasil observasi, wawancara untuk meningkatkan pemahaman penelitian tentang kasus yang diteliti.

\section{HASIL DAN PEMBAHASAN}

Hasil dari analisis data yang dilakukan di Koperasi Dewan Kemakmuran Masjid At-Taqwa Desa Cicadas yaitu, bahwa pada dasarnya semua bentuk muamalah boleh dilakukan kecuali ada dalil yang mengharamkannya. Pelaksanaan pembiayaan modal usaha di Koperasi Dewan Kemakmuran Masjid At-Taqwa sudah sesuai dengan syariah, meskipun masih ada beberapa diantaranya yang belum memenuhi kriteria syariah.

Penyaluran dana yang diterapkan dalam pembiayaan modal usaha di Koperasi seharusnya berasal dari dana simpanan. Tetapi, hasil dari analisis data yang diteliti oleh Peneliti yang dilakukan di Koperasi Dewan Kemakmuran Masjid At-Taqwa yaitu penyaluran dana yang berasal dari Donatur dan Kas Masjid.

Maka dari itu, seharusnya pelaksanaan di Koperasi Dewan Kemakmuran Masjid At-Taqwa Desa Cicadas harus lebih diperhatikan dan diperbaiki dalam penerapan pembiayaan modal usaha tersebut sehingga pembiayaan yang dilakukan Koperasi Dewan Kemakmuran Masjid At-Taqwa Desa Cicadas berjalan lebih baik lagi dengan menerapkan prinsip-prinsip Syariah Islam.

Adapun kesimpulan dari hasil wawancara dengan Bapak Haeri selaku Ketua Dewan Kemakmuran Masjid At-Taqwa Desa Cicadas mengenai pembiayaan tersebut menggunakan akad mudharabah yaitu bahwa pelaksanaan akad mudharabah pada pembiayaan modal usaha di Koperasi DKM At-Taqwa Desa Cicadas merupakan salah satu solusi bagi masyarakat dalam mengembangkan potensi atau usaha yang sedang membutuhkan tambahan modal dalam mengembangkan usahanya tersebut. Karena dengan adanya pembiayaan tersebut dapat membantu setiap anggota atau masyarakat dalam 
mengembangkan usahanya dan bisa menanggulangi masalah pada masyarakat dari kemiskinan, pengangguran dan lain-lain. Selain daripada itu masyarakat juga tidak akan terjerumus ke dalam hal yang negatif atau melanggar aturan ajaran Islam karena dalam pembiayaan di Koperasi DKM At-Taqwa Desa Cicadas ini dilaksanakan sesuai dengan prinsip syariat Islam.

Pembiayaan akad mudharabah merupakan pembiayaan yang banyak digunakan diberbagai lembaga. Diantaranya di Koperasi DKM ATTaqwa Desa Cicadas. Dalam pelaksanaannya, banyak hal yang harus diperhatikan terutama dalam persyaratan maupun kelengkapan dalam melakukan pengajuan permohonan pembiayaan tersebut. Dalam pembiayaannya harus pula sesuai prosedur pengajuan prosedur yang ada dan sesuai dengan alur pengajuan pembiayaan tersebut (Haeri, 2019).

Selanjutnya dalam usaha yang akan diberikan pembiayaan tidaklah sembarang usaha. Karena usaha yang dibiayai sudah berjalan minimal satu tahun. Dengan estimasi bahwa usaha yang telah berjalan dikatakan sehat atau dapat ditekan sedemikian mungkin jika terjadi kemacetan.

Pembiayaan akad mudharabah di Koperasi Dewan Kemakuran Masjid At-Taqwa Desa Cicadas ini menggunakan prinsip mudharabah muqayyadah, yaitu pemilik dana (shahibul maal) membatasi/memberi syarat kepada mudharib dalam pengelolaan dana seperti misalnya hanya untuk melakukan mudharabah bidang tertentu, cara, waktu, dan tempat tertentu saja hanya untuk membiayai modal kerja dari usaha tertentu.

Bagi hasil adalah pembagian atas keuntungan antara anggota dengan koperasi syariah yang ditetapkan berdasarkan kesepakatan dua belah pihak.

Pelaksanaan akad mudharabah pada pembiayaan modal usaha di Koperasi DKM AtTaqwa Desa Cicadas bertujuan untuk meringankan masyarakat pada umunya dan anggota pada khususnya dalam melakukan pembiayaan agar terhindar dari rentenir dan bunga berlebihan (Haeri, 2019).

Menurut peraturan dalam KJKS (Koperasi Jasa Keuangan Syariah) pola pembiayaan bagi hasil Mudharabah adalah akad kerjasama usaha perniagaan antara pihak pemilik dana (shahibul maal) sebagai pihak yang menyediakan modal dana sebesar $100 \%$ dengan pihak pengelola modal (mudharib), untuk diusahakan dengan porsi (nisbah) keuntungan akan dibagi bersama sesuai dengan kesepakatan dimuka dari kedua belah pihak, sedangkan kerugian (jika ada) akan ditanggung pemilik modal, kecuali jika diketemukan adanya kelalaian atau kesalahan oleh pihak pengelola dana (mudharib), seperti penyelewengan, kecurangan, dan penyalah gunaan dana.

Mekanisme penghitungan bagi hasil menurut ekonomi islam idealnya ada dua macam yaitu Profit Sharing, dan Revenue Sharing.

Pembagian hasil atau keuntungan yang dilakukan di Koperasi DKM At-Taqwa Desa Cicadas ini yaitu menggunakan prinsip syariah Profit Sharing. Profit Sharing yaitu penentuan besarnya rasio atau nisbah berdasar atas keuntungan yang diperoleh secara nyata.

Gambar 3. Skema Bagi Hasil Koperasi Dewan Kemakmuran Masjid At-Taqwa

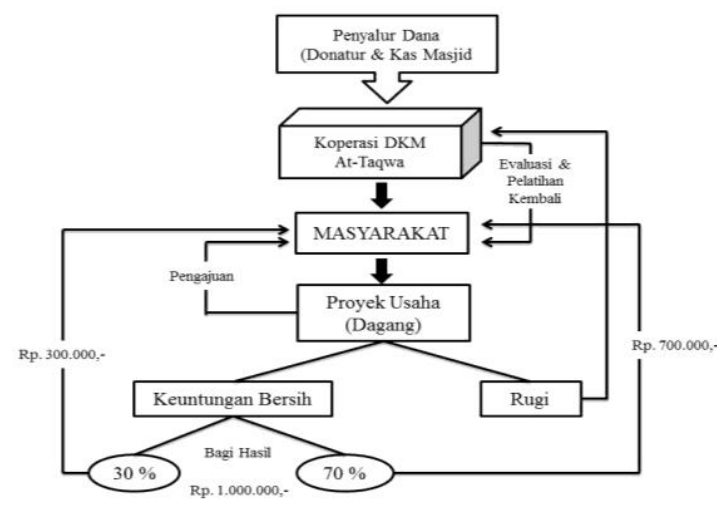

Sumber: Diolah oleh Peneliti Tahun 2019

Dapat disimpulkan bahwa pembagian hasil yang dilakukan di Koperasi DKM At-Taqwa Desa Cicadas yaitu bagi hasil yang diambil dari keuntungan bersih yang sudah dipotong oleh biaya-biaya pengeluaran lain dengan pembagian 30\% untuk Koperasi DKM itu sendiri dan 70\% untuk masyarakat/mudharib. Tetapi jika hasilnya didapati rugi, maka dari pihak koperasi akan melakukan evaluasi atau pelatihan kembali supaya usahanya tersebut tidak mengalami kerugian.

Untuk meningkatkan produktifitas dan daya saing usaha kecil, salah satu faktor penunjang terpenting adalah ketersediaan modal yang cukup. Kendala permodalan bagi umumnya pengusaha kecil, tidak mampu dipenuhi oleh perbankan modern. Oleh karena itu, Koperasi DKM AtTaqwa hadir di tengah-tengah masyarakat untuk 
EKSISBANK Vol. 3 No. 2 Desember 2019

membantu masyarakat yang membutuhkan dana bagi usahanya.

Ada beberapa dampak yang timbul karena adanya pelaksanaan akad mudharabah pada pembiayaan modal usaha di Koperasi DKM AtTaqwa Desa Cicadas, yaitu diantaranya ada dampak bagi pengelola, dampak bag masayarakat atau anggota, dan dampak bagi pertumbuhan ekonomi.

\section{KESIMPULAN}

Pelaksanaan akad mudharabah pada pembiayaan modal usaha di Koperasi Dewan Kemamuran Masjid At-Taqwa Desa Cicadas menggunakan prinsip mudharabah muqayyadah, yaitu di mana pemilik dana memberi syarat kepada mudharib dalam pengelolaan dana misalnya hanya untuk melakukan pembiayaan dibidang usaha tertentu, cara, waktu, dan tempat tertentu saja. Dalam pelaksanaannya pun terdapat beberapa persyaratan dan kelengkapan yang harus diperhatikan, seperti melengkapi berkas-berkas persyaratan untuk melakukan pengajuan pembiayaan yang harus dilakukan sesuai dengan prosedur pengajuan pembiayaan mudharabah yang ada di Kopersi DKM AtTaqwa Desa Cicadas.

Pembagian hasil yang dilakukan di Koperasi Dewan Kemamuran Masjid At-Taqwa Desa Cicadas yaitu bagi hasil yang diambil dari keuntungan bersih yang sudah dipotong oleh biaya-biaya pengeluaran lain (Profit Sharing) dengan pembagian 30\% untuk Koperasi Dewan Kemamuran Masjid At-Taqwa Desa Cicadas itu sendiri dan $70 \%$ untuk mudharib. Tetapi jika hasilnya didapati ada kerugian, maka dari pihak koperasi akan melakukan evaluasi atau pelatihan kembali supaya usahanya tersebut tidak mengalami kerugian. Dan pembayaran angsuran dilakukan dengan jangka waktu sesuai dengan kemampuan pengusaha/mudharib, sesuai dengan kesepakatan yang dibuat oleh kedua-belah pihak.

Dampak dari pelaksanaan pembiayaan mudharabah pada masyarakat nyatanya dirasakan jelas oleh masyarakat sekitar Desa Cicadas. Dengan adanya pembiayaan tersebut mereka bisa dengan tenang menjalankan usaha yang mereka kelola tanpa adanya kekhawatiran dalam melaksanakannya, karena pembiayaan yang mereka jalankan merupkan pembiayaan yang menggunakan prinsip syariah Islam.

\section{DAFTAR PUSTAKA}

Abdullah, B. (2010). Peradaban Pemikiran Ekonomi Islam. CV Pustaka Setia.

Al-Asqalany, A.-H. I. I. H. (2019). Bulughul Maram Min Adillatil Ahkaam (3.01 ed.). Madrasah Tsanawiyah Persis Sukasari.

Antonio, M. S. (2001). Bank Syariah Dari Teori Ke Praktik. Gema Insani Press.

Arikunto, S. (2013). Prosedur Penelitian. PT. Asdi Mahasatya.

Haeri. (2019). Wawancara tentang Sejarah Lembaga Koperasi Dewan Kemakmuran Masjid At-Taqwa Subang. Koperasi Dewan Kemakmuran Masjid At-Taqwa.

Hakim, A. A. (2011). Fiqih Perbankan syariah. Pt. Refika Aditama. 